\title{
POSSIBILIDADES DE INTERVENÇÃO DO ASSISTENTE SOCIAL NA EDUCAÇÃO BÁSICA COM BASE NA LEI N. ${ }^{0}$ 13.935/2019
}

Possibilities Social Worker's intervention in school based on law no. 13.935/2019

Posibilidades de intervención de asistente social en la escuela basada en la ley ${ }^{\circ}{ }^{\circ}$ $13.935 / 2019$

Received: july/2020

Accepted: august/2020

Available online: september/2020

Bruna Carolina de Souza, Acadêmica de Serviço Social, Centro Universitário Leonardo da Vinci, Brasil

E-mail: brunacarolinadesz@.gmail.com.

Cláudio Adão da Rosa, Mestre em Educação, Instituto Federal de Santa Catarina, Brasil.

E-mail: claudioadarosa@gmail.com

\begin{abstract}
Resumo: O objetivo deste artigo foi analisar possibilidades de intervenção do assistente social na educação, com base na lei 13.935/2019 que garante o profissional de Serviço Social nas escolas de educação básica. Para alcançar tal objetivo, foi desenvolvida uma pesquisa exploratória, com referencial teórico ancorado em autores como Martins (1999; 2007), Novais et al (2001) e Oliveira et al (2015). Para contribuir com o alcance do objetivo proposto, foi realizada, também, a aplicação de um questionário para a assistente social de uma secretária de educação de um município do Planalto Norte Catarinense sobre sua experiência e seus entendimentos em relação às possibilidades de intervenção neste campo de atuação. Os resultados apontaram que, embora as indicações de possibilidades de intervenção do Assistente Social na educação básica discutidas neste artigo sejam, em boa parte, anteriores à lei n. ${ }^{\circ}$ 13.935/2019, não existem grandes desencontros teórico-metodológicos com a lei atual. Entretanto, como o objetivo proposto foi analisar as possibilidades de intervenção do Assistente Social com base na lei n. ${ }^{\circ}$ 13.935/2019, essa carência de elementos impossibilitou a contemplação do objetivo em sua totalidade. Mostrando uma clara evidencia da necessidade emergente de mais pesquisas que discutam este assunto.
\end{abstract}


Palavras-chave: Serviço Social na Educação, Lei n. ${ }^{0}$ 13.935/2019, Intervenção do Assistente Social.

\begin{abstract}
The purpose of this article was to analyze the possibilities of intervention of the social worker in education, based on the law 13.935 / 2019 that guarantees the professional of Social Work in schools of basic education. To achieve this goal, an exploratory research was developed, with a theoretical framework anchored in authors such as Martins (1999; 2007), Novais et al (2001) and Oliveira et al (2015). In order to contribute to the achievement of the proposed objective, a questionnaire was also applied to the social worker of an education secretary in a municipality in the Planalto Norte Catarinense about her experience and her understandings regarding the possibilities of intervention in this field. performance. The results showed that, although the indications of possibilities for Social Worker intervention in basic education discussed in this article are, to a large extent, prior to Law No. 13.935 / 2019, there are no major theoretical and methodological disagreements with the current law. However, as the proposed objective was to analyze the intervention possibilities of the Social Worker based on Law No. 13,935 / 2019, this lack of elements made it impossible to contemplate the objective in its entirety. Showing clear evidence of the emerging need for more research to discuss this issue.
\end{abstract}

Keywords: Social Work in Education, Law no. 13.935/2019, Social Worker's Intervention.

Resumen: El propósito de este artículo fue analizar las posibilidades de intervención del trabajador social en educación, en base a la ley 13.935 / 2019 que garantiza al profesional del Trabajo Social en las escuelas de educación básica. Para lograr este objetivo, se desarrolló una investigación exploratoria, con un marco teórico anclado en autores como Martins (1999; 2007), Novais et al (2001) y Oliveira et al (2015). Con el fin de contribuir al logro del objetivo propuesto, también se aplicó un cuestionario a la trabajadora social de una secretaria de educación en un municipio del Planalto Norte Catarinense sobre su experiencia y su comprensión sobre las posibilidades de intervención en este campo. actuación. Los resultados mostraron que, aunque las indicaciones de posibilidades para la intervención del trabajador social en la educación básica discutidas en este artículo son, en gran medida, anteriores a la Ley $\mathrm{N}{ }^{\circ} 13.935 / 2019$, no existen desacuerdos teóricos y metodológicos importantes con la ley actual. Sin embargo, como el objetivo propuesto era analizar las posibilidades de intervención del Trabajador Social con base en la Ley $\mathrm{N}^{\circ} 13.935$ / 2019, esta falta de elementos hizo imposible contemplar el objetivo en su totalidad. Mostrar evidencia clara de la necesidad emergente de más investigación para discutir este tema.

Palabras clave: Trabajo Social en Educación, Ley N ${ }^{\circ}$ 13.935/2019, Intervención del Trabajador Social.

\title{
INTRODUÇÃO
}

A garantia do direito à Educação no Brasil, ainda é um assunto recorrente nas discussões sobre as políticas públicas. Isto ocorre porque, embora as legislações tragam em seus textos o direito ao acesso para todos os cidadãos, independente de suas condições biopsicossociais, na prática, devido a fatores socioeconômicos, condições de saneamento básico, renda, transporte, entre outros, esse direito não tem se efetivado em sua totalidade.

Sabendo dessa carência, neste artigo articulamos os conhecimentos do campo do Serviço Social (SS) para contribuir com o campo da Educação, entendendo que os 
profissionais dessa área possuem competências específicas que vão ao encontro da luta pelo acesso universal à Educação. Diante deste contexto, o objetivo deste artigo é discutir possibilidades de intervenção dos assistentes sociais na educação básica com base na lei n. ${ }^{\circ}$ $13.935 / 2019$.

Para alcançar o objetivo, primeiramente foi realizada uma revisão bibliográfica em artigos científicos e nas legislações que tratam da atuação dos profissionais de serviço social na educação. E, em seguida, por meio de abordagem qualitativa, realizamos uma pesquisa exploratória, aplicando um questionário para assistente social da Secretaria de Educação do município de Canoinhas - SC, sobre sua experiência e seus entendimentos relacionados às possibilidades de intervenção deste profissional no campo da educação básica.

\section{O DIREITO À EDUCAÇÃO NO BRASIL}

Nem sempre na história da humanidade o acesso à educação formal foi um direito de todos. Ao contrário disso, a história mostra o quão recente são os movimentos pela universalização do acesso à educação no mundo. Um dos primeiros registros da luta por essa democratização ocorreu somente em 1948, por meio da Declaração Universal dos Direitos Humanos, que estabelece em seu Art. $1^{\circ}$ que todos os seres humanos nascem livres e iguais em dignidade e em direitos; em seu Art. $7^{\circ}$ que todos são iguais perante a lei e, sem distinção, têm direito a igual proteção da lei; e, em seu Art. $26^{\circ}$ que toda a pessoa tem direito à educação (ONU, 1948).

O Brasil é um dos países signatários desta Declaração e, baseando-se nela, estabeleceu alguns marcos legais para que o direito ao acesso universal à educação ocorresse de fato no país. Nesse sentido, as leis de diretrizes e bases da educação nacional de 1961 e 1971 (BRASIL, 1961; BRASIL, 1971) já traziam em seus textos a intenção de promover uma 
educação para todos. No entanto, somente a partir da Constituição Federal (CF) de 1988 (BRASIL, 1988) que o Brasil assumiu um compromisso mais firme com a ideia de construir políticas públicas de acesso e permanência em sistemas de ensino formais pelas populações que até então eram excluídas desses espaços. Isto se evidencia no Art. 205 e 206 da CF, quando dizem que

\begin{abstract}
Art. 205. A educação, direito de todos e dever do Estado e da família, será promovida e incentivada com a colaboração da sociedade, visando ao pleno desenvolvimento da pessoa, seu preparo para o exercício da cidadania e sua qualificação para o trabalho.

Art. 206. O ensino será ministrado com base nos seguintes princípios:

I - igualdade de condições para o acesso e permanência na escola;

II - liberdade de aprender, ensinar, pesquisar e divulgar o pensamento, a arte e o saber;

III - pluralismo de idéias e de concepções pedagógicas, e coexistência de instituições públicas e privadas de ensino;

IV - gratuidade do ensino público em estabelecimentos oficiais; educação, direito de todos e dever do Estado e da família, será promovida e incentivada com a colaboração da sociedade, visando ao pleno desenvolvimento da pessoa, seu preparo para o exercício da cidadania e sua qualificação para o trabalho [...] (BRASIL, 1988, Art. $5^{\circ}$ e Art. $\left.6^{\circ}\right)$.
\end{abstract}

Os movimentos de luta pela garantia do direito à educação ganharam força em todo o mundo após a realização da Conferência Mundial de Educação para Todos realizada em 1990 na Tailândia, de onde saiu a Declaração de Jomten (UNICEF, 1990) que expressou em seu texto que a educação é um direito de todos, mulheres e homens, de todas as idades, no mundo inteiro. Ainda nessa década, no ano de 1996 foi promulgada no Brasil a atual Lei de Diretrizes e Bases da Educação Nacional (LDBEN) (BRASIL, 1996), que rege todos os sistemas de ensino no Brasil, onde é reforçado o compromisso da garantia do direito de todos à educação

Art. $5^{\circ} \mathrm{O}$ acesso à educação básica obrigatória é direito público subjetivo, podendo qualquer cidadão, grupo de cidadãos, associação comunitária, organização sindical, entidade de classe ou outra legalmente constituída e, ainda, o Ministério Público, acionar o poder público para exigi-lo (BRASIL, 1996, Art. $5^{\circ}$ ).

Embora essa garantia esteja presente em diversas legislações, até mesmo na Constituição Federal, na prática, o que se observa é que, devido a diversos fatores, alguns 
grupos sociais ainda não têm, de fato, esse direito garantido, sobretudo os grupos de minorias historicamente marginalizados pela sociedade, como as pessoas com deficiência, os negros e os indígenas, por exemplo.

Para combater essa exclusão, alguns movimentos sociais vêm se mobilizando para pressionar os poderes legislativos e executivos para a criação de mecanismos que ampliem o leque de oportunidades educacionais destinadas à população mais vulnerável. Esse movimento é o impulsionador da criação de novas legislações, como é o caso da lei n. ${ }^{o}$ 13.935/2019 (BRASIL, 2019) que dispõe sobre a prestação de serviços de psicologia e de serviço social nas redes públicas de educação básica.

Nesse sentido, não havia um dispositivo legal que obrigasse os sistemas de ensino a contratratarem esses profissionais. Mesmo com o prazo de um ano dado pela lei para que os sistemas de ensino se organizem já na metade, ainda não é possível notar movimentos expressivos dos gestores públicos para cumprir o que ela pede.

\begin{abstract}
Art. $1^{\circ}$ as redes públicas de educação básica contarão com serviços de psicologia e de serviço social para atender às necessidades e prioridades definidas pelas políticas de educação, por meio de equipes multiprofissionais. $\S 1^{\circ}$ As equipes multiprofissionais deverão desenvolver ações para a melhoria da qualidade do processo de ensino-aprendizagem, com a participação da comunidade escolar, atuando na mediação das relações sociais e institucionais. $\S 2^{\circ} \mathrm{O}$ trabalho da equipe multiprofissional deverá considerar o projeto político-pedagógico das redes públicas de educação básica e dos seus estabelecimentos de ensino (BRASIL, 2019, Art. $1^{\circ}$ ).
\end{abstract}

Considerando que o trabalho dessas equipes multiprofissionais precisa estar articulado com o projeto político-pedagógico dos estabelecimentos de ensino das redes públicas de educação básica, e o caráter recente da lei, ainda não há publicações científicas contundentes que analisam como esse trabalho aconteceria na prática, portanto, foi necessário buscar pesquisas anteriores à lei n. ${ }^{\circ}$ 13.935/2019 para fazer as reflexões sobre a atuação profissional do assistente social nesse campo de trabalho. 
Conforme aponta Oliveira et al (2015) foi somente a partir da década de 1990 que houve um aumento considerável de discussões e pesquisas sobre o Serviço Social na área da educação. Ao final dessa década, com base nessas experiências iniciais, Martins (1999) elencou alguns objetivos da prática profissional do serviço Social no setor educacional:

- Melhorar as condições de vida e sobrevivência das famílias e alunos;

- Favorecer a abertura de canais de interferência dos sujeitos nos processos decisórios da escola (os conselhos de classe);

- Ampliar o acervo de informações e conhecimentos, acerca do social na comunidade escolar;

- Estimular a vivência e o aprendizado do processo democrático no interior da escola e com a comunidade;

- Fortalecer as ações coletivas;

- Efetivar pesquisas que possam contribuir com a análise da realidade social dos alunos e de suas famílias;

- Maximizar a utilização dos recursos da comunidade;

- Contribuir com a formação profissional de novos assistentes sociais, disponibilizando campo de estágio adequado às novas exigências do perfil profissional.

No início dos anos 2000, Novais et al (2001) destacavam que, apesar da escola ser um dos principais equipamentos sociais, existia um número pequeno de profissionais de Serviço Social atuando na área. Conforme os autores, o Serviço Social tem a possibilidade de contribuir com a realização de diagnósticos sociais, indicando possíveis alterações à problemática social vivida pelos alunos, o que refletirá na melhoria de suas condições de 
enfrentamento da vida escolar. Essa atuação pode ser, por exemplo, no combate à evasão escolar, em atitudes e comportamentos agressivos ou de risco, etc.

Na contemporaneidade, a luta pela efetivação do Serviço Social na educação está legitimada pela necessidade de trabalhar com a multiplicidade de expressões da questão social que perpassam a educação. Nesse sentido, autores como Dentz e Silva (2015), destacam que o trabalho tem se dado no sentido de fortalecer as redes de sociabilidade e de acesso aos serviços sociais e dos processos sócio-institucionais voltados para o reconhecimento e aplicação dos direitos dos sujeitos sociais. Dessa forma, o profissional de serviço social pode atuar na orientação social com as famílias e alunos, sobre as políticas públicas e suas formas de acesso para garantir os direitos sociais, trabalhando também com a rede socioassistencial.

Oliveira et al (2015) reforçam o entendimento das discussões sobre a importância e a capacidade que a educação tem para mudar uma sociedade, para formar cidadãos críticos, competentes, capazes de se reconhecerem como sujeitos de direitos, e que tenham capacidade de reivindicar, de lutar pela concretização de seus direitos. É nesse contexto que a intervenção do assistente social nas escolas se faz imprescindível, uma vez que são diversos os fatores que justificam sua intervenção nesses ambientes, dentre eles a própria função social da escola, bem como a educação como um direito social e a contribuição do Serviço Social na garantia desse direito.

Os autores destacam ainda que:

\begin{abstract}
A profissão de caráter sócio-político, crítico e interventivo tem como objetivo justamente atuar nas expressões da questão social, que vem com a contribuição de diversas ciências, sendo algumas delas: sociologia, psicologia, economia, ciência política, antropologia e ética. Através de uma intervenção investigativa, pesquisa e análise social, atua não somente na avaliação, mas também da elaboração e execução de projetos, planos, programas, políticas sociais, e de serviços (OLIVEIRA et al, 2015, p. 126).
\end{abstract}

Com base na realidade socioeducacional brasileira e nas considerações apresentadas pelos autores, entende-se que é fundamental que o serviço social participe de forma efetiva na 
construção das políticas educacionais, intervindo e propondo estratégias que busquem a transformação social no sentido de eliminar todas as formas de violação dos direitos sociais, como é o caso da educação. O resultado esperado com este processo é que cada vez mais construída e solidificada a ideia de sistemas de ensino inclusivos, onde todos, independentemente de suas condições, possam usufruir com sucesso.

\section{MATERIAIS E MÉTODOS}

A pesquisa realizada foi de abordagem qualitativa, pois tem como característica a compreensão de um fenômeno em seu sentido mais intenso (RAUEN, 2015). Referente aos objetivos traçados é caracterizada como exploratória, por ser, conforme Gil (2008), um estudo que tem como objetivo propor uma melhor familiarização com o problema pesquisado, para torná-lo mais claro.

Como sujeito de pesquisa participou a Assistente Social do município de Canoinhas SC, que é Graduada em Serviço Social em 1983 e Especialista em Metodologia do Serviço Social e Psicopedagogia. Trabalha atualmente na Secretaria Municipal de Educação e está nesta área há 30 anos.

Por causa da situação da pandemia de Covid-19 atual, e a recomendação de distanciamento social, foi utilizado como instrumento de coleta de dados um questionário em que, primeiramente coletamos os dados de identificação, como: ano de formação, área e tempo de atuação, local de trabalho e formação. Em seguida são apresentadas quatro questões sobre as experiências na área da educação. As análises das respostas ocorreram de forma descritiva, articulando-as com a literatura científica que trata do assunto e com a legislação.

\section{RESULTADOS E DISCUSSÃO}


A coleta de dados foi realizada por meio de entrevista com questões abertas, assim, para melhor interpretar os resultados, cada resposta é discutida individualmente, articulada com a literatura científica que fundamenta o referencial teórico proposto nesta pesquisa. Desse modo, abaixo são apresentadas as questões A, B, C e D, seguidas de suas respostas e das suas análises.

Questão A: Que atribuições você como profissional de serviço social tem na área da educação?

Assistente Social: Todas as especificadas no Plano de Cargos, Carreira, salários e Remuneração do Magistério e dos profissionais da Educação do Município de Canoinhas/SC Lei Complementar 038/2011 de 14/11/2011, em consonância com as Legislações pertinentes ao profissional Assistente Social.

Observa-se na resposta que o município em que ela atua profissionalmente já contém regulamentações sobre a atuação do assistente social na educação. Essas regulamentações vão ao encontro do que apresenta Oliveira et al (2015), quando afirma que, historicamente as possibilidades de atuação os profissionais de serviço social estão nas manifestações da questão social, como é o caso das políticas educacionais, tendo a competência para planejar, propor, elaborar, coordenar e executar ações, projetos e programas sociais, na ampla realidade social e institucional.

Questão B: Quais instrumentos técnicos operativos você utiliza e qual a finalidade de cada um na sua intervenção profissional?

Assistente Social: Em relação ao meu trabalho como Assistente Social ao Educando, utilizo os instrumentais que entendo necessário a cada caso e de acordo com a intervenção que se pretende desenvolver, podendo ser desde um atendimento individual ou grupal, uma visita domiciliar ou institucional, uma entrevista, um acompanhamento social, participação em reuniões, elaboração de projetos e relatórios, dentre outros. Em relação à finalidade de cada um, está associada ao objetivo que se pretende obter, por exemplo, se for preciso obter mais dados para entender o contexto em que o individuo vive, a visita domiciliar com contatos de familiares, amigos e vizinhos, locais que frequenta unidade de ensino onde estuda dentre outros, são importantes neste procedimento.

Conforme Martins (2007), o processo de trabalho do assistente social está no seu instrumental 
técnico-operativo, no entanto essas técnicas não estão somente relacionadas ao tecnicismo, mas também ao seu conhecimento teórico-metodológico para a aplicação do mesmo. A resposta corrobora com essa afirmativa, visto que ela utiliza diferentes formas de envolvimento com alunos, famílias e instituições que atende. Ampliando assim o conhecimento sobre as realidades vivenciadas por cada grupo e possibilitando a organização de ações mais assertivas.

Questão C: Quais diretrizes legais norteiam sua atuação profissional?

Assistente Social: As que apontam principalmente para a compreensão do significado social da profissão, com perfil ético e apreensão teórico-crítica.

A importância de seguir diretrizes que têm a compreensão do significado social alinha-se ao entendimento de Yazbek (2009), que em seu texto aponta como necessário ultrapassar a análise do Serviço Social para um contexto de relações mais amplas que constituem a sociedade capitalista, particularmente, no âmbito das respostas que esta sociedade e o Estado constroem, frente à questão social e às suas manifestações, em múltiplas dimensões.

Questão D: Com base no seu conhecimento na área da educação comente sobre as possibilidades de intervenção profissional baseada na lei 13.935/2019.

Assistente Social: Em nosso Município, por meio de Lei, desde 1990, o Assistente Social integra o Grupo de Apoio ao Magistério, sendo que demais profissionais psicólogos e fonoaudiólogos, também passaram a compor a Rede a partir do ano 2000. Hoje fazemos parte dos profissionais que integram a Rede Municipal de Educação de Canoinhas. Considero de suma importância esta conquista, pois é um espaço que oportuniza de maneira objetiva, a orientação em relação à garantia de direitos e deveres de nossos educandos e seus pares, principalmente. $E$ um serviço existente em Canoinhas que se coloca como referência para muitos outros municípios, que ainda não tem legalmente constituído estes profissionais fazendo parte do quadro da Educação. Espero que a partir da referida Lei (13.935/2019), tenhamos os profissionais Assistentes Sociais, incluídos nos Quadros de Profissionais da Educação em todo nosso país. 
As intervenções realizadas estão articuladas com as orientações de Novais et al (2001) quando dizem que as contribuições fundamentais dadas pelo profissional de serviço social estão especialmente vinculadas a proporcionar o devido encaminhamento aos serviços sociais e assistenciais. Neste caso em especial, em que a Assistente Social faz parte do quadro que compõe a rede municipal de ensino, essas intervenções estão relacionadas à garantia de direito dos alunos e seus familiares à educação, principalmente instruindo-os sobre esses direitos e fazendo os devidos encaminhamentos para a rede socioassistencial.

No entanto, sobre as possibilidades de intervenção com base na lei n. ${ }^{\circ}$ 13.935/2019, a entrevista, com base nas contribuições que vem fazendo em seu município, apenas indica uma expectativa positiva no sentido de ampliação do número de profissionais de Serviço Social que poderão fazer parte das redes de ensino de todo o país. Ela não fez apontamentos sobre situações que poderiam influenciar em uma atuação diferente dos profissionais de Serviço Social, do que já havia anteriormente a lei. Isto pode direcionar para um entendimento de que ainda são necessárias discussões sobre a operacionalização do trabalho desse profissional na prática, com base nessa lei.

\section{CONCLUSÃO}

Com base na literatura sobre a trajetória da garantia do direito à educação no Brasil, verificamos que esse direito nem sempre chegou a todos, e que a luta pela democratização do acesso foi um processo lento, conduzido pela influência de movimentos internacionais que lutaram por uma educação para todos.

Um dos marcos mais efetivos para garantir o acesso universal no à educação no Brasil ocorreu com a promulgação da Constituição Federal de 1988, que em seu Art. 205 prevê a RBPPD/BRJPD | Vol. 2 | n. 3 | p. 106-119, 2020. 
educação como um direito de todos e dever do estado e da família. Alguns anos depois, a Lei de Diretrizes e Bases da Educação Nacional, publicada em 1996, que rege todos os sistemas de ensino do Brasil, reforçou o compromisso com a garantia do direito de todos ao acesso a educação.

Nossa pesquisa mostrou que, mesmo com o direito registrado em legislações, na prática, em razão de diversos fatores, alguns grupos de minorias historicamente marginalizadas ainda não têm, de fato, acesso à educação. A partir deste contexto e após muita persistência de movimentos sociais interessados na ampliação do acesso à educação, houve a homologação da lei n. ${ }^{\circ}$ 13.935/2019, que dispõe sobre a prestação de serviços de psicologia e de serviço social nas redes públicas de educação básica.

Devido ao caráter recente dessa lei, ainda há carência de um referencial teórico consistente capaz de analisar os impactos da atuação dos Assistentes Sociais na educação básica com base nas suas diretrizes. Assim, o embasamento teórico utilizado para realizar as discussões foi construído por publicações anteriores à lei. Nesse sentido, as respostas da assistente social entrevistada também foram com base em construções teóricas e orientações anteriores.

Os apontamentos feitos pela entrevista sobre as possibilidades de atuação do Assistente Social na educação básica indicaram a necessidade de compreensão do significado social da profissão na garantia dos direitos educacionais e que é possível utilizar diferentes formas de envolvimento com alunos, famílias e instituições para ampliar o conhecimento sobre as realidades vivenciadas por cada grupo e possibilitar a organização de ações mais assertivas.

Concluímos que, embora as indicações de possibilidades de intervenção do Assistente Social estejam, em boa parte, ancoradas em regulamentações anteriores à lei n. ${ }^{\circ}$ 13.935/2019, não há grandes desencontros com a lei atual. Entretanto, como o objetivo proposto foi analisar RBPPD/BRJPD | Vol. 2 | n. 3 | p. 106-119, 2020. 
as possibilidades de intervenção do Assistente Social com base, especificamente na lei n. ${ }^{\circ}$ 13.935/2019, houve uma carência de elementos impossibilitou a contemplação do objetivo em sua totalidade. Mostrando uma clara evidencia da necessidade emergente de mais pesquisas que discutam este assunto.

\section{REFERÊNCIAS}

BRASIL. Constituição da República Federativa do Brasil. Brasília: Imprensa Oficial, 1988. Disponível em: http://www.planalto.gov.br/ccivil 03/constituicao/constituicao.htm. Acesso em: 14/06/2020.

Lei n. 9394, de 20 de dezembro de 1996. Estabelece Diretrizes e Bases da educação nacional. Diário Oficial [da] República federativa do Brasil. Poder Legislativo, Brasília/DF, 23 de dez. 1996. Seção 1, n. 248, p. 27833 - 27841.

Lei n. 13.935 de 11 de Dezembro de 2019. Dispõe sobre a prestação de serviços de psicologia e de serviço social nas redes públicas de educação básica. Disponível em: http://www.planalto.gov.br/ccivil 03/ ato2019-2022/2019/1ei/L13935.htm. Acesso em: $19 / 05 / 2020$.

. Ministério da Educação. Lei de Diretrizes e Bases da Educação Nacional (LDB). 4.024, de 20 de dezembro de 1961. Disponível em: http://www.planalto.gov.br/ccivil 03/leis/L4024.htm. Acesso em: 13/06/2020.

. Ministério da Educação. Lei de Diretrizes e Bases da Educação Nacional (LDB). Lei n. 5.692, de 11 de agosto de 1971. Disponível em: http://www.planalto.gov.br/ccivil_03/leis/15692.htm. Acesso em: 13/06/2020.

DENTZ, M. V; SILVA, R. R. D. Dimensões históricas das relações entre educação e Serviço Social: elementos para uma revisão crítica. Serv. Soc. Soc., São Paulo, n. 121, p. 7-31, jan./mar. 2015. Disponível em:

https://www.scielo.br/pdf/sssoc/n121/0101-6628-sssoc-n121-0007.pdf. Acesso em: 23/05/2020.

GIL, A.C. Como elaborar projetos de pesquisa. $4^{\text {a }}$ edição. São Paulo. Atlas, 2008

MARTINS, E. B. C. Educação e Serviço Social: Elo para a construção da Cidadania, 2007.

MARTINS, E. B. C. O Serviço Social na área da Educação. Revista Serviço Social \&

Realidade, v. 8, n 1. UNESP, Franca: São Paulo, 1999. Disponível em:

https://periodicos.franca.unesp.br/index.php/SSR. Acesso em: 20/06/2020.

NOVAIS, L. C. C., et al. Serviço Social na educação. Conselho Federal de Serviço Social (CFESS), 2001. 
OLIVEIRA, A. C. A; et al. A inserção do serviço social na educação: uma ponte para a afirmação das políticas públicas de inclusão. Revista Includere, Mossoró, v. 1, n. 1, p. 117-127, Ed. Especial, 2015. Disponível em:

https://periodicos.ufersa.edu.br/index.php/includere/article/view/4592. Acesso em:

20/05/2020.

ORGANIZAÇÕES DAS NAÇÕES UNIDAS (ONU). Declaração Universal dos Direitos Humanos. 1948. Disponível em:

http://www.onu-brasil.org.br/documentos direitoshu-manos.php. Acesso em: 20/05/2020.

RAUEN, F. Roteiros de pesquisa. Rio do Sul, SC: Nova Era, 2015.

UNICEF. Declaração Mundial sobre Educação para Todos: plano de ação para satisfazer as necessidades básicas de aprendizagem, Jomtiem/Tailândia, 1990. Disponível em:

https://www.unicef.org/brazil/declaracao-mundial-sobre-educacao-para-todos-conferencia-dejomtien-1990. Acesso em: 17/06/2020.

YAZBEK, M. C. O significado sócio-histórico da profissão. In: Serviço Social: direitos sociais e competências profissionais. - Brasília: CFESS/ABEPSS, 2009. (125- 163) 